\title{
МЕТАФОРА КАК ВИД РЕГУЛЯРНОЙ ПОЛИСЕМИИ
}

\section{METAPHOR AS A TYPE OF REGULAR POLYSEMIA}

\section{E. Potsybina}

Summary: The article is devoted to the problem of the metaphor theory. The article describes the mechanisms for creating a metaphor based on agricultural vocabulary in two non-closely related languages: Russian and English. Metaphor is interpreted as a source of polysemia, as a means of developing new lexical meanings within a separate thematic group.

Keywords: metaphor theory, a semantic word structure, component analysis, context analysis, types of metaphorical transference, comparative linguistic analysis.

\author{
Поцыбина Елена Павловна \\ к.филол.н., дочент, Московский государственный \\ университет имени М.В. Ломоносова \\ elena.potsybina@yandex.ru
}

Аннотация: Статья посвящена проблеме теории метафоры. В статье описаны механизмы создания метафоры на основе земледельческой лексики в двух неблизкородственных языках: русском и английском. Метафора трактуется как источник возникновения полисемии, как средство развития новых лексических значений в рамках отдельной тематической группы.

Ключевые слова: теория метафоры, семантическая структура слова, компонентный анализ, контекстологическй анализ, типы метафорических переносов, сопоставительно- лингвистический анализ.
$\mathrm{M}$ етафора - это механизм образования новых лексических значений на основе существующих лексических единиц. На этом основании метафору, в частности языковую метафору, можно рассматривать как вид регулярной полисемии. Изучения полисемии имеет прагматическую ценность: полисемия тесно связана с коммуникативной и познавательной функцией языка [10, с.267].

Языковая метафора является важным объектом лингвистического исследования, так как, отражая обычные жизненные явления и «коллективно осознанные способы их характеристики» и классифицируя элементы действительности, она участвует в одном ряду с другими лексическими в общем для всего народа членении этой действительности [2, с.25].

Изучение метафоры было и остается актуальным, причем, в современной лингвистике наметилась тенденция изучения метафорической лексики в пределах тематических и семантических групп. Такой подход приобретает особую значимость при проведении сопоставительного исследования в рамках ограниченной лексической группы. При сопоставлении малых систем в двух языках предоставляется возможным определить лексический элемент каждой системы и его функциональных связей с другими элементами системы [7; 12, с.10].

Нами было проведено сопоставительное лингвистическое исследование с целью изучения метафорики глаголов, обозначающих процессы земледельческого труда на материале русского и английского языков. В качестве объекта исследования тематическая группа земледельческой лексики была избрана по ряду причин. Во-первых, земледельческая лексика относится к древнейшему пласту лексической системы. Она диахронически устойчива, отражает важные процессы в жизни человека и общества. В интерлингвальном значении является универсальной и относится к наиболее продуктивным тематическим группам сравниваемых языков: русского и английского. Глаголы этой группы являются полными эквивалентами в основном, прямом, номинативном значении, что существенно для проведения сопоставительного анализа. Эквивалентными в теории лингвистки, как известно, считаются слова с межъязыковыми лексическими понятиями, то есть понятиями, которые присутствуют в двух этнокультурных общностях и без искажения информации адекватно выражаются на двух разных языках [1, с.16-17]. Во- вторых, глаголы, обозначающие процессы земледельческого труда, являются лексическими константами и связаны с практическим опытом всех народов мира. Они представлены во многих языках и существуют на протяжении многих веков [8, c. 43]. Земледельческая лексика отражает насущные для жизни общества процессы и относится к разряду частотной. В языке, как отмечают некоторые лингвисты, слова, обозначающие важные социальные явления, приобретают большую семантическую активность, расширяют сферу использования. Было отмечено, что метафорические переносы наименований наиболее интенсивно затрагивают те группы лексики, которые связаны с насущными и важными для жизни общества явлениями [11, с.95].

Для проведения сопоставительного исследования, рассмотрения плана выражения и плана содержания изучаемых лексических единиц данной тематической группы использовался метод компонентного анализа и метод контекстологического анализа. Метод компонентного анализа, суть которого заключается в разложении лексического значения на минимальные семантические 
составляющие, семы, позволяет изучить семантическую структуру многозначного слова и выделить переносные значения, составляющие основу языковой метафоры [9, с 41]. Метод контекстологического анализа в данном исследовании был необходим для описания глагольных метафор, в процессе актуализации которых важная роль принадлежит контексту. Глагольная метафора имеет свою специфику. Обозначая какое-либо явление, глагольная метафора использует денотативные или коннотативные элементы семантической структуры глагола, а также отдельные признаки слов окружающего контекста. Этот тип метафоры синтаксически связан: в актуализации метафоры значительную роль играют актанты.

Эмпирической базой настоящего исследования послужили данные толковых словарей в русском и английском языках, материалы Большой картотеки Словарного отдела Института лингвистических исследований РАН, а также данные лингвистических корпусов [4; 5; 8]. Наше исследование мы начали с рассмотрения и сопоставления семантических структур эквивалентных глаголов, обозначающих начало обработки земли: to plough - naхать и их производных. Компонентный анализ сопоставляемых глаголов позволил выявить состав семем изучаемых глаголов, провести сравнение и сделать выводы о наличии общих и специфических, существующих только в одном из языков, лексических значений. Изучение семантики земледельческих глаголов осуществлялось на материале толковых словарей английского и русского языков. Словарная статья английского глагола to plough в толковом словаре английского языка [OED] наиболее полно отражает состав лексических значений этого глагола, часть из которых, отмеченных пометой trans, представляют переносное значение.

\section{To plough}

1. To cut and turn up the soil, to make furrows in the earth with a plough( разрыхлять и переворачивать слой почвы, создавать борозды при помощи плуга) е.g. They have ploughed and fitted for graingrowing 3.000acres [OED, vol.VII: 1006].

2. Trans - to gash, to tear up any surface (нарушать, разрывать любую поверхность) е.g. The line-engraver ... month after month ploughs slowly his marvelous lines [OED, vol. VII: 1006].

3. Trans. / of a ship, boat, swimming animal (разрезать поверхность воды) e.g. The steamer ... ploughed her way across the blue and rushing waters of the Minch [OED, vol.VII: 1006].

4. Trans. -to wrinkle face, to furrow face (покрывать, испещрять лицо морщинами) e.g. Her face rough and ploughed with wrinkles.[ OED, vol.VII : 1006]

5. Trans / slang/ - to reject a candidate as not reaching the pass standard in an examination (отклонить кандидатуру экзаменуемого как несоответствующую требованиям, предъявляемым на экзамене.) е.g
My young friend was undeservedly ploughed [ OED, vol.VII : 1007].

Итак, семантическая структура английского глагола to plough содержит целый ряд метафорических значений. К ним относятся следующие:

- нарушать, прорезать любую твердую поверхность;

- разрезать поверхность воды, скользить по воде;

- покрывать, испещрять лицо морщинами;

- отклонять кандидатуру, несоответствующую определенным выдвигаемым требованиям.

Каждое из этих метафорических значений имеет свою мотивирующую сему, объединяющую исходное и метафорическое значение. Смыслообразующую нагрузку в перечисленных метафорических значениях выполняют дифференциальные семы, отражающие отличный от основного значения глагола способ действия и сопутствующие ему актанты, субъекты и объекты действия. На основе приведенных выше примеров становится очевидным тот факт, что отличительной чертой каждой из рассматриваемых глагольных метафор выступает способ действия непохожий на способ действия, выраженного в исходном значении глагола, а также субъекты и объекты действия, которые значительно отличаются от нормативных актантов в основном значении глагола.

В семантической структуре эквивалентного русского глагола пахать представлено несколько значений.

Пахать - 1. взрыхлять, переворачивая пласт земли сохой или плугом или другими специальными орудиями для посева

Поворачивай лучше оглобли и возвращайся в деревню землю пахать, вместо того чтобы тут гнить [П. Катаев. Алмазный мой венец] // НКРЯ//

2. перен. действовать, работать на совесть, упорно [Ожегов, 1990:494]

«Я очень устал, так как целый день пахал на огороде» // Короленко «История моего современника» - (из материалов БКСО)

«В лаборатории мы пахали вчера целый день» (материалы БКСО).

Согласно данным толковых словарей русского языка глагол пахать имеет только одно метафорическое значение - упорно, добросовестно трудиться. Эта метафора в русском языке используется как экспрессивный синоним лексических единиц, передающих понятие работать, совершать какой-либо род деятельности. От единиц этого синонимического ряда метафора пахать 
отличается особой коннотацией, в которой находит отражение оценка интенсивности труда и относится к разряду разговорной лексики. Подчеркиваются такие характеристики, как упорный, тяжелый, продолжительный труд. Основу этого метафорического значения глагола naxamb образуют ассоциации, связанные с изнурительным трудом земледельца. Это метафора характерна только для русского языка, эквивалентный английский глагол не обладает таким переносным значением. В семантике русского глагола пахать выделяется еще одно метафорическое значение, которое не относится к широкоупотребительным и не нашло отражение в словарях русского языка. Оно образует лексическую параллель с переносным значением глагола to plough - - to cleave the surface of the water - разрезать поверхность воды, скользuть по воде. В русском языке эта метафора встречается в литературных произведениях и разговорной речи. « Рыбаки моря глубоко пашут. Круглый год качает их волна.» [Прокофьев. Во имя мира.] «Броненосец шел своим ходом, распахивая воды чужого моря» [Новиков - Прибой. Цусима] (материалы БКСО).

Осуществляя сравнение семантической структуры эквивалентных глаголов to plough - naxamb, которые обладают в основном своем значении единством семантического ядра, нам удалось выяснить сходство и различие их метафорики, установить степень активности в метафорообразовании каждого из глаголов, выявить параллельные переносные значения. Было установлено, что английский глагол to plough имеет больше метафорических значений, чем его русский эквивалент. При этом, каждый из рассматриваемых глаголов имеет метафорические значения, передающие определенную национальную специфику и характерную только для одного из языков. У английского глагола to plough - это значение - to reject a candidate as not reaching the pass standard in an examination (отклонить кандидатуру экзаменуемого как несоответствующую требованиям, предъявляемым на экзамене). У русского глагола пахать - специфичной, свойственной только русскому языку, является метафора - действовать, работать на совесть, упорно. В семантике этих глаголов обнаружены и параллельные переносные значения, которые образуются от основных, базовых глаголов - to plough - naxamb (разрезать noверхность воды, скользить по воде, а также параллельные значения образуются от некоторых производных глаголов. Для проведения наиболее полного и объективного сопоставительного исследования целесообразно изучить метафорику производных глаголов, образующих словообразовательные гнезда сопоставляемых базовых глаголов. Такой подход вполне оправдан, так как в теории лингвистики существует положение о том, что однокоренные слова большей частью имеют схожие потенции к метафоризации.

К производным английского глагола to plough отно- сятся фразовые глаголы: to plough back, to plough into, to plough on, to plough through.

Согласно данным фразеологического словаря Longman Dictionary of Phrasal Verbs фразовый глагол to plough back имеет прямое и переносное значение:

\section{To plough back - LDPhV}

1. To return the remains of the crop to the earth with a plough- закапывать остатки урожая в землю , используя плуг e.g. ...there were a lot of loose leaves lying on the field, so the farmer ploughed them back to enrich the soil

2. Trans. to return (money earned) into business so as to increase it - вкладывать деньги в бизнес с целью его увеличения е.g. There is very little to show for the first year's work as we have ploughed back all the profits into methods of increasing trade next year.

Сравнение прямого и переносного значений дает возможность определить механизм образования метафоры. Метафорическое значение соотносится с новым денотатом, отличным от денотата прямого значения глагола. Компонентный анализ показывает, что оба значения имеют общую схему to return something somewhere (вернуть что-либо куда-то). В переносном значении эта сема теряет свою силу, переходит в разряд периферийной, дополняется новой схемой in order to get profit для получения прибыли. В результате на основе слияния двух сем образуется метафорическое значение, основу которого составляет новая сема - to return something somewhere in order to get profit - возвратить что-либо куда-либо с иелью получения прибыли Итак, как следует из приведенных выше примеров, метафорические переносы приводят к появлению новых лексических значений, непосредственно способствуют развитию лексической полисемии.

Фразовый глагол to plough into имеет три значения, два из которых метафорические.

\section{To plough into}

1. To bury; to mix something such as the remains of a crop with the earth with a plough - захоронить; смешать с землей , используя плуг е.g. After the wheat crop has been gathered, many farmers burn the remains and plough the ash into the soil, so as to enrich the soil [LDPHV, 433].

2. Trans. to start work actively - приняться активно за работу e.g. If I really plough into my studies now, I should be ready for the examination [LDPHV, 433].

3. To strike against something or someone with force - налететь на что-либо или кого - либо, с силой удариться о что-либо или кого- либо е.g. The car turned over twice, left the road and ploughed into a fence. 
В семантической структуре глагола to plough into выделяются два метафорических значения, отличающиеся от исходного значения глагола. Актуализация приведенных метафорических значений происходит за счет появления нового денотата, изменяется характер действия и объект действия. Частица into в составе фразового глагола также влияет на семантику переносных значений, активизируя периферийную сему направления движения. У фразового глагола to plough on семантика всех его значений содержит сему частицы оn, обозначающее продолжение какого- либо действия.

\section{To plough on}

1. To continue to turn the earth with a plough- продолжать переворачивать землю е.g. If we plough on until it is dark, we shall get this field finished [LDPhV,p.433]

2. Trans to continue to advance with determination peшительно продолжать что-либо е.g. We must plough on somehow in spite of all difficulties

Сопоставляя оба значения, образованных от фразового глагола to plough on, следует отметить, что их объединяет общая сема " to continue to do something" (продолжать делать что-либо), к которой в метафорическом значении присоединяется новая сема, подчеркивающая характер совершаемого действия " to do something with determination" (делать что-либо решительно, с твердым намерением). В английском языке, как отмечено в словаре фразовых глаголов, это метафорическое значение может быть передано синонимами: to press on, to push ahead, to push on. "We must plough on (press on, push on...) with work, if we are to finish it in time" [LDPhV,433].

Фразовый глагол to plough through имеет только переносные значения, Его семантическую структуру образует два значения.

\section{To plough through -}

1. To move slowly with difficulty through, to force one's way through something- медленно, с трудом продвигаться сквозь что-либо е.g. It took over an hour to reach the farmhouse, ploughing through the deep snow in my high boots [LDPhV, 433] e.g. The ship rolled as she ploughed her way through the stormy sea [LDPhV, 433]

2. to get slowly to the end of; to make one's way with difficulty through something ( such as work)- медленно, с трудом завершать что-либо е.g. I doubt if I shall be home for dinner; I have suddenly a lot of urgent work to plough through. e.g. She spent the weekend ploughing her way through the pile of lettersthat she owed to people [LDPhV,433].

Метафорические значения, образованные от фразового глагола to plough through, имеют разные денотаты.
Первое значение обозначает процесс движения, характеризуя при этом тип движения - медленный, сопряженный с определенными трудностями. Второе значение относится к разновидности деятельности, совершения которого также связано с преодолением определенных трудностей. Вполне очевидно, что это два разных лексических значения, но их объединяет сема глагольной частицы through - to overcome difficulties, которая актуализируется в обоих значениях, переходя из разряда периферийных в ядерную, смыслообразующую.

В русском языке производные от глагола naxamb представлены глаголами, основным словообразовательным формантом в которых выступает префикс, смысловая нагрузка которого изменяет значение слова. Результаты исследования показали, что метафорическим значением обладают глаголы с префиксом om (omnaxamb,) nepe (nepenaxamb) u pac (pacnaxamb).

Метафора, источником которой стал глагол оmnaxamb, относится к числу языковых. Она имеет помету разг в словаре, указывающую на ее принадлежность к сниженному, разговорному стилю. Эта метафора представляет собой семантическую модификацию общеупотребительной в разговорной речи метафоры глагола пахать - упорно, тяжело трудиться «Он отпахал на заводе тридиать лет»; «Я уже свое отпахал». В каждом из примеров метафора передает значение «отработал, сделал что-то». Это значение актуализируется за счет семантики приставки «от», указывающей на завершения действия. Метафора отпахать эмоционально окрашена, обладает ярко выраженной экспрессией и содержит элементы оценки: труд оценивается как сложная, требующая больших физических затрат деятельность.

Метафора, образованная от глагола nepenaxamb, также является семантической производной от глагола пахать и имеет значение «сделать что-либо с большими усилиями, в большом количестве» «Я перепахал столько литературы, прежде чем нашел нужный мне пример»; «Он перепахал много словарей, но так и не нашел этого значения слова». Дополнительное семантическое значение в этой метафоре актуализируется под влиянием семы приставки пере -, чрезмерность, излишество действия [БТС. 792]

Метафорическое значение глагола расnaxamb тесно связано с прямым значением глагола naxamb, когда он используется для описания обработки земли - разрывать, взрыхлять землю. Ядерная сема прямого значения глагола становится символом метафоры, что приводит к появлению нового метафорического значения. «Молния полностью распахала взбугренную черную тучу, долго копилась тишина» [М. Шолохов. Тихий Дон кн.3]; «Я семнадцать лет бревна резал, вот и рожу мне пила распахала» [А.М. Горький. Отшельник]; «Выпуклый лоб глубоко 
распахан морщинами, на голове буйно торчат жесткие клочья сивых волос» [А.М. Горький. Ветеринар] // БКСО//

Результаты проведенного исследования позволяют сделать следующий вывод: глаголы, обозначающие процесс вспашки земли, to plough - naxamb, и их произво- дные способны к метафоробразованию. На их основе появился целый ряд языковых метафор, активно использующихся в речи. Часть из них образуют лексические параллели, встречаются в английском и русском языках, но большая часть метафор входит в лексический состав только одного из сопоставляемых языков.

\section{ЛИТЕРАТУРА}

1. Верещагин Е.М., Костомаров В.Г. Лингвострановедческая теория слова. - М.: Русский язык, 1980. - 320 с.

2. Виноградов В.В. Основные этапы становления лексических значений слова// ВЯ, 1953, № 5. С. 3-29.

3. Виноградов В.В. Лексикология и лексикография. - М.: Наука, 1977. - 370 с.

4. Гак В.Г. Метафора: универсальная и специфическая// Метафора в языке и тексте. - М.: Наука, 1988. - С. 11-26.

5. Зевахина Т.С. Сопоставительный анализ образной семантики лексических систем. - М.: МАКС Пресс, 2011. - 144 с.

6. Лещева Л.М. Лексическая полисемия в когнитивном аспекте. - М.: Языки славянской культуры; b, 2014. - 256 c.

7. Мельничук М.В., Осипова В.М. Метафора в англоязычном бизнес-дискурсе // Научный диалог. 2015. № 11 (47). С. 31-41.

8. Материальная культура. - М.: Наука. 1989. - 222 с.

9. Стернин И.А. Лексическое значения слова в речи. - Воронеж; Изд-во Воронежского университета, 1985. - 170 с.

10. Ульман С. Семантические универсалии // Новое в лингвистике. Вып. 5. - М.: Прогресс, 1970. С 267

11. Шмелев Д.Н. Современный русский язык. Лексика. - М.: Наука,1977. -335 с.

12. Ярцева В.Н. 0 сопоставительном методе изучения языков // НДВШ, Филолог, 1960, № 1. - С. 3 - 15.

1. БАС - Словарь современного русского литературного языка (в 17-ти томах).

2. БКСО - Большая картотека Словарного отдела ИЛИ РАН

3. БТС - Большой толковый словарь русского языка. - СПб.: «Норинт», 2002. - 1536 с.

4. НКРЯ - Национальный корпус русского языка- http: //www.ruscorpora.ru;

5. COCA- Corpus of Contemporary American English (COCA) http : // corpus.byu.edu/coca //

6. LDPhV - Longman Dictionary of Phrasal Verbs, 1986.-734 p.

7. Oxford English Corpus - http: // oxforddictionaries.com/words/ the- oxford-english-co//

8. OED-The oxford English Dictionary.- Oxford: Calender Press, 1989, v. I- XVI

9. OERD- The Oxford English Reference Dictionary, 2ed. Oxford, New York, 1996

( П) Поцыбина Елена Павловна (elena.potsybina@yandex.ru). 